\title{
Fusarium head blight and trichothecene production in wheat by Fusarium graminearum and $F$. meridionale applied alone or in mixture at post-flowering
}

\author{
Camila P. Nicolli ${ }^{1}$ - Piérri Spolti ${ }^{1}$ - Casiane S. Tibola ${ }^{2}$ - José Maurício C. Fernandes ${ }^{2}$. \\ Emerson M. Del Ponte ${ }^{1,3}$
}

Received: 20 January 2015 / Accepted: 10 April 2015 /Published online: 9 May 2015

(C) Sociedade Brasileira de Fitopatologia 2015

\begin{abstract}
A greenhouse study was conducted to expand our knowledge of the disease and mycotoxin production by Fusarium graminearum (Fgra) and F. meridionale (Fmer) inoculated at post-flowering, either alone or in equal mixture, into three cultivars varying in their reaction to Fusarium head blight (FHB) in the field. In the first experiment, the entire spike was spray-inoculated and the proportion of diseased spikes (or incidence, INC) was monitored up to 15 days after inoculation (dai). In the second experiment, the inoculum was dispensed into the central-spikelet and the proportion of disease spikelets (or severity, SEV) was evaluated at 15 dai. The inoculum composition and the inoculum $\mathrm{x}$ cultivar interaction on both experiments were not significant. However, BRS 194, a standard for susceptibility, had significantly higher INC and SEV than BRS Parrudo and BRS 179, the latter a standard for moderate resistance. Fmer was less damaging to grain yield than Fgra and grain yield of BRS Parrudo was the least affected among the cultivars. Trichothecenes (DON + NIV) were detected in both experiments, irrespectively of the cultivar, at levels up to 2,000 and $15,000 \mu \mathrm{g} / \mathrm{kg}$, in the spray-inoculation and central-spikelet inoculation experiment, respectively. Fgra alone produced only DON and Fgra+Fmer produced mainly DON and small amount of NIV. Fmer produced mainly NIV, but also trace amounts of
\end{abstract}

Section Editor: Adalberto Café

Emerson M. Del Ponte

delponte@ufv.br

1 Departamento de Fitossanidade, Universidade Federal do Rio Grande do Sul, 91540-000 Porto Alegre, RS, Brasil

2 Embrapa Trigo - Empresa Brasileira de Pesquisa Agropecuária, 99001-970 Passo Fundo, RS, Brasil

3 Present address: Departamento de Fitopatologia, Universidade Federal de Viçosa, 36570-000 Viçosa, MG, Brasil
DON. Our results suggest that post-flowering infections may contribute with trichothecenes in mature grain, especially DON. Nevertheless, NIV should be considered in analytical surveys due to its high toxicity.

Keywords Triticum aestivum · Deoxynivalenol · Nivalenol · FGSC

\section{Introduction}

Fusarium head blight (FHB) is a major concern to wheat production worldwide not only because of grain yield losses but also due to the presence of dangerous mycotoxins in harvested grain (McMullen et al. 2012). Deoxynivalenol (DON), a type$\mathrm{B}$ trichothecene, is the most significant mycotoxin given its widespread occurrence in wheat grain at levels of concern (Del Ponte et al. 2012). Such problem has led to the establishment of maximum tolerance limits of DON in small grains and byproducts in North America (Miller et al. 2013), Europe (Cheli et al. 2014) and Brazil (ANVISA 2011). However, nivalenol (NIV), another trichothecene mycotoxin, has been found at equal or higher concentrations than DON in the Netherlands, Japan and Brazil (Tanaka et al. 1990; Thammawong et al. 2010; Del Ponte et al. 2012).

Members of the Fusarium graminearum species complex (FGSC) are the main cause of FHB worldwide (O'Donnell et al. 2004; Aoki et al. 2012). FGSC isolates are known to possess three specific profiles of trichothecene production, or chemotypes (chemical phenotype), including: nivalenol (NIV) and its acetyl-derivatives, DON and primarily 3acetyl(A)deoxynivalenol(DON), and DON and primarily 15ADON (Miller et al. 1991). PCR-based assays targeting portions of genes predictive of trichothecene synthesis have been used to determine the trichothecene genotype as predictive of 
the chemotype (Desjardins 2008). While some FGSC members are fixated for only one trichothecene genotype (e.g., F. meridionale) others may segregate for two or three different genotypes (e.g., F. graminearum and F. asiaticum) (Aoki et al. 2012).

Fusarium graminearum sensu stricto (hereafter F. graminearum) is the main species associated with FHB of wheat in the Americas (Ramirez et al. 2007; Ward et al. 2008; Schmale et al. 2011; Umpiérrez-Failache et al. 2013; Del Ponte et al. 2015). In Brazil, molecular surveys conducted during the last decade showed that isolates of the dominant F. graminearum populations possesses the 15-ADON genotype ( $>80 \%$ of prevalence) (Astolfi et al. 2011, 2012; Del Ponte et al. 2015). Four other species (F. meridionale, $F$. cortaderiae, F. austroamericanum and $F$. asiaticum) that commonly posses the NIV genotype are also found but in relatively lower frequency overall (Del Ponte et al. 2015). However, evidence that F. meridionale occur at high frequency in the state of Paraná and F. cortaderiae in the northeastern regions of Rio Grande do Sul state (Del Ponte et al. 2015), may have significant implications for food safety and the economics of cereal production since NIV mycotoxin has been reported to have higher toxicity than DON (Desjardins 2006).

In previous studies, saprophytic (asexual growth) and pathogenic fitness traits of Brazilian isolates of $F$. graminearum (15-ADON) and F. meridionale (NIV) have been compared, with some fitness advantages being attributed to the former (Spolti et al. 2012; Spolti and Del Ponte 2013). It is not well understood whether the Brazilian isolates of the DON and NIV genotypes produce only the respective main trichothecene form during pathogenesis. Nevertheless, both DON and NIV have been found in commercial wheat grain (Del Ponte et al. 2012) but knowledge specific to these species is lacking. Available information on chemical analysis of cultures of Brazilian isolates of $F$. graminearum sensu lato is limited and although NIV was not detected (Geraldo et al. 2006), results were not accompanied by genetic analysis of the strains. In a recent study, NIV and DON have been quantified from in vitro growth of these species on artificial media (Pagnussatt et al. 2014). In addition, there is a lack of knowledge of the risk of mycotoxin production by the Brazilian FGSC isolates resulting from infections that take place after flowering, when crop susceptibility tends to decrease for most cultivars (McMullen et al. 2012). A study conducted using a highly susceptible cultivar suggested that plump kernels resulting from successful post-flowering infections may be more difficult to eliminate during harvesting and cleaning, thus contributing with mycotoxin in the grain (Del Ponte et al. 2007). In the present study, we aimed at expanding the knowledge of the toxigenic ability of isolates by assessing measures of FHB intensity, damage potential and the relative contribution of trichothecene production by two species of the complex inoculated at post-flowering, either alone or in equal mixture, into three wheat varieties known to possess distinct levels of susceptibility to FHB.

\section{Material and methods}

\section{Isolates and cultivars}

Six isolates, being three $F$. graminearum of the $15-\mathrm{ADON}$ genotype (Fgra; 09Tr006; 10Tr008; 10Tr084) and three $F$. meridionale of the NIV genotype (Fmer; 07Tr205, 09Tr092, 09Tr109), were selected from a larger collection from a survey conducted during 3 years in the northern region of Rio Grande do Sul state, Brazil (Astolfi et al. 2012; Del Ponte et al. 2015).

Three EMBRAPA cultivars were selected for this study. Two were released commercially in the 1999-2000 period (Caierão et al. 2014): BRS 194, a standard for susceptibility and BRS 179, a standard for moderate resistance, based on breeding information, greenhouse and field studies (Lima et al. 2005, 2007; Spolti et al. 2012). The third, BRS Parrudo, is a short-height cultivar released commercially in 2014 and known to combine high response to nitrogen fertilization and resistance to lodging, and moderate resistance to fungal diseases, including FHB (based only on field observations by Caierão et al. 2014). Ten seeds were sown per pot $(5 \mathrm{~L})$ containing soil substrate (equal parts of humus, soil and vermiculite) fertilized with macronutrients (NPK in a ratio of 10:10:10). Potted plants were maintained in the greenhouse from sowing to maturity. In the greenhouse, the mean daily temperature was $\pm 25^{\circ} \mathrm{C}$, mean minimum temperature $\pm 20^{\circ} \mathrm{C}$, and mean relative humidity was $\pm 60 \%$ during the course of the experiments.

\section{Inoculum preparation and inoculation}

Inoculum was produced in SNA (Spezieller Nährstoffarmer Agar) media as described previously and consisted of a macroconidial suspension $\left(1 \times 10^{5}\right.$ spores $\left./ \mathrm{ml}\right)$ (Spolti et al. 2012). Inoculations were performed when plants reached the early milk stage, around 2 weeks after onset of flowering. Two separate experiments were conducted, 20 days apart from each other, using two methods of inoculation. In the first, each spike was spray-inoculated with a hand-sprayer until run-off. In the second, a 20-ml drop of inoculum was dispensed into the central spikelet using a micropipette (Spolti et al. 2012). Three inoculum compositions were tested: a) mixture of three Fgra isolates inoculated alone; b) mixture of three Fmer isolates inoculated alone; and c) equal mixture of the six isolates (Fgra+Fmer). Non-inoculated plants were used as a check treatment and for estimating relative reduction in kernel weight (RKW). Immediately after inoculation, plants from 
the same pot were covered with a plastic bag (to induce wetness) for $48 \mathrm{~h}$ at $25^{\circ} \mathrm{C}$. Then, the bags were removed and the plants maintained in the greenhouse until maturity. For each experiment, there were eight pots (each pot as a replication) with 4 to 7 spikes per treatment.

\section{Disease and yield assessments and mycotoxin analysis}

In the spray-inoculation experiment, FHB incidence (or the proportion of diseased spikes) was evaluated at 5, 10 and 15 days after inoculation. In the central-spikelet inoculation experiment, FHB severity (or the proportion of diseased spikelets in a spike) was evaluated at 15 days after inoculation. When plants reached maturity, kernels were harvested, handthreshed and dried to $13 \%$ grain moisture. A subsample of 100 grains from each treatment was surface-disinfested and subjected to standard seed health blotter test for the assessment of the Fusarium kernel infection (FKI). Another subsample of 100 grains was examined and Fusarium-damaged kernels (FDK) separated from visibly healthy kernels and both fractions weighed. The ratio between the weight of diseased kernels and healthy kernels was calculated and expressed in percentage FDK.

A pooled sample of kernels $(50 \mathrm{~g})$ from the same treatment (cultivar $\mathrm{x}$ inocula) was sent for mycotoxin analysis (Instituto Samitec, Santa Maria, RS) using an UPLC/MS-MS method as described by Varga et al. (2012). The method had a limit of detection (LOD) and a percentage recovery for DON and NIV, of $200 \mu \mathrm{g} / \mathrm{kg}$ and $80 \%$, and $100 \mu \mathrm{g} / \mathrm{kg}$ and $74 \%$, respectively.

\section{Experimental design and data analysis}

Each experiment was a $3 \times 3$ factorial in a completely randomized design with eight replicates. A generalized linear model with a Gaussian link function was used to test for single and interaction effects $(P<0.05)$ of factors (cultivar and inoculum composition). The variables evaluated were FHB incidence estimated 10 days after spray-inoculation and final FHB severity estimated at 15 days after central-spikelet inoculation. Contrasts of interest were tested using the generalized linear hypothesis test function of the multcomp package of $\mathrm{R}$ (The $\mathrm{R}$ Project for Statistical Computing).

Because a pooled sample across all replicates of a treatment was analyzed for FKI, FDK, RKW and DON and NIV content, standard statistical analysis could not be conducted. Hence, descriptive statistics and graphs were used to summarize and depict the data. Pearson's correlation coefficient and the respective $95 \%$ confidence interval were calculated for the mean or absolute values of all variables of the experiments combined. In this combined analysis FHB incidence and severity were treated as a single disease intensity measure.

\section{Results}

\section{Disease-related variables}

The generalized linear model showed evidence that both FHB incidence and severity varied significantly across the cultivars $(P<0.05)$, while the null hypothesis could not be rejected for inoculum composition and the interaction factor $(P>0.05)$. In the central-spikelet experiment, the disease progressed slowly to a few spikelets beyond the inoculated spikelet. The mean final severity ranged from 7 to $14 \%$ on average across the cultivars (Fig. 1a). In the spray-inoculation experiment, FHB incidence increased up to 40 and $60 \%$ on average at 10 days after inoculation (Fig. 1b). The ranking of the cultivars was similar among the experiments with BRS 194 exhibiting higher disease levels than the other two cultivars (Fig. 1a).

The percent of FDK ranged from 7 to $22 \%$ in the centralspikelet experiment (Fig. 2a) and from 10 to $30 \%$ in the sprayinoculation experiment (Fig. 2c) across the cultivars. The levels of FKI ranged from 8 to $25 \%$ in the central-spikelet inoculation experiment (Fig. 2a) and from 40 to $80 \%$ in the spray-inoculation experiment (Fig. 2c). FKI levels appeared higher in BRS 194 than the other cultivars in the spray inoculation experiment (Fig. 2c).

\section{Yield-related variables and mycotoxin production}

For most cultivars there was a trend of Fgra inoculated alone most often leading to the higher RKW levels than the mix and Fmer alone (Fig. 2a and c). Among the cultivars, Parrudo had the least RKW (Fig. 2c). The total amount of trichothecenes (DON + NIV) ranged from 500 to $2500 \mu \mathrm{g} / \mathrm{kg}$ (ppb) in kernels from the central-spikelet inoculation experiment (Fig. 2b) and from 2,000 to $15,000 \mu \mathrm{g} / \mathrm{kg}$ in kernels from the sprayinoculation experiment (Fig. 2d). Among the cultivars, BRS 194 accumulated more mycotoxin than the other cultivars (Fig. $2 b$ and d). Kernels from plants inoculated with Fgra alone were contaminated only with DON. Kernels inoculated with Fmer were contaminated mainly with NIV but trace amount of DON, especially in the spray-inoculation experiment was also found. DON was the main mycotoxin found in kernels from plants inoculated with the mix of the two species (Fgra+Fmer), but small amounts of NIV were also detected (Fig. 2c and d).

\section{Correlation analysis}

Correlation analysis for all pairs of variables showed the strongest association $(r=0.95)$ between visual disease intensity (DIS) and FKI and moderate associations ( $r=0.65$ to 0.7$)$ between total trichothecenes and FKI, between total trichothecenes and RKW and between FKI and RKW (Fig. 3). 

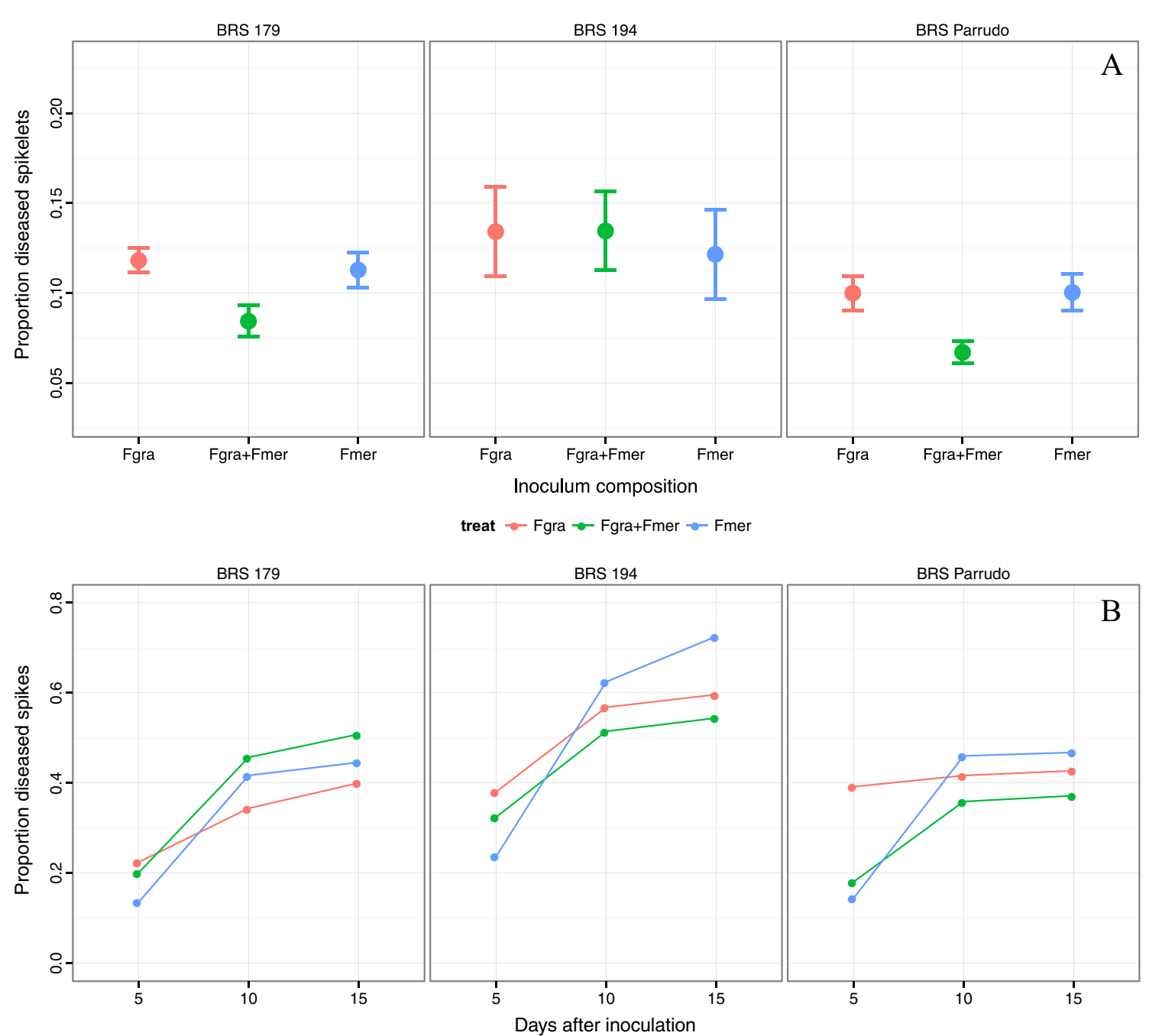

Fig. 1 Mean (standard error) values of Fusarium head blight (FHB) severity (proportion of diseased spikelets) (a) and Mean FHB incidence (proportion of diseased spikes) (b) on three EMBRAPA BRS cultivars inoculated at the early milk stage with three inoculum compositions (treat): Fusarium graminearum (Fgra) alone, F. meridionale (Fmer),

\section{Discussion}

In this study we showed that Fgra and Fmer isolates were capable of infecting wheat cultivars at the early milk stage and producing DON and NIV at relatively high levels, especially when plants were spray-inoculated. When inoculum is sprayed over the entire spike, multiple infection sites may establish and the disease spread more quickly over the entire spike, even when inoculated during grain filling stages of a highly susceptible cultivar (Del Ponte et al. 2007). In our study, disease was detected in some spikes more than 5 days after inoculation but still 40 to $50 \%$ of the inoculated spikes did not exhibit symptoms. This may be due to resistance mechanisms and differences among plants/spikes related to phenology or uncontrolled environmental factors. Susceptibility to FHB, in general, tends to decrease after flowering, which may explain the lower range in disease alone, and the mixture of the two species (Fgra + Fmer (a). In A, plants were inoculated using the central-spikelet inoculation method. In B, plants were spray-inoculated and evaluated at three times after inoculation. Note that maximum value of the $y$ axis is different in the graphs

severity (around $11 \%$ mean severity) in our study compared to severity measured in plants inoculated during flowering (around $50 \%$ mean severity) (Spolti et al. 2012). Nevertheless, the incidence and severity levels reached in our study is close to the highest severity (10 to $18 \%$ ) found in five commercial wheat fields, in a sample of 160 fields surveyed in the region during 3 years (Spolti et al. 2015), and where natural infections may occur at multiple times from flowering to grain filling stages, depending on the weather (Del Ponte et al. 2004). The differences we found among the cultivars, although significant, were not dramatic, likely due to low disease levels. Nevertheless, BRS 194 and BRS 179 exhibited the highest and lowest incidence and severity, respectively, agreeing with previous resistance classification (Lima et al. 2007; Spolti et al. 2012; Spolti and Del Ponte 2013).

Differences in aggressiveness among FGSC members towards wheat, which is commonly determined using the 

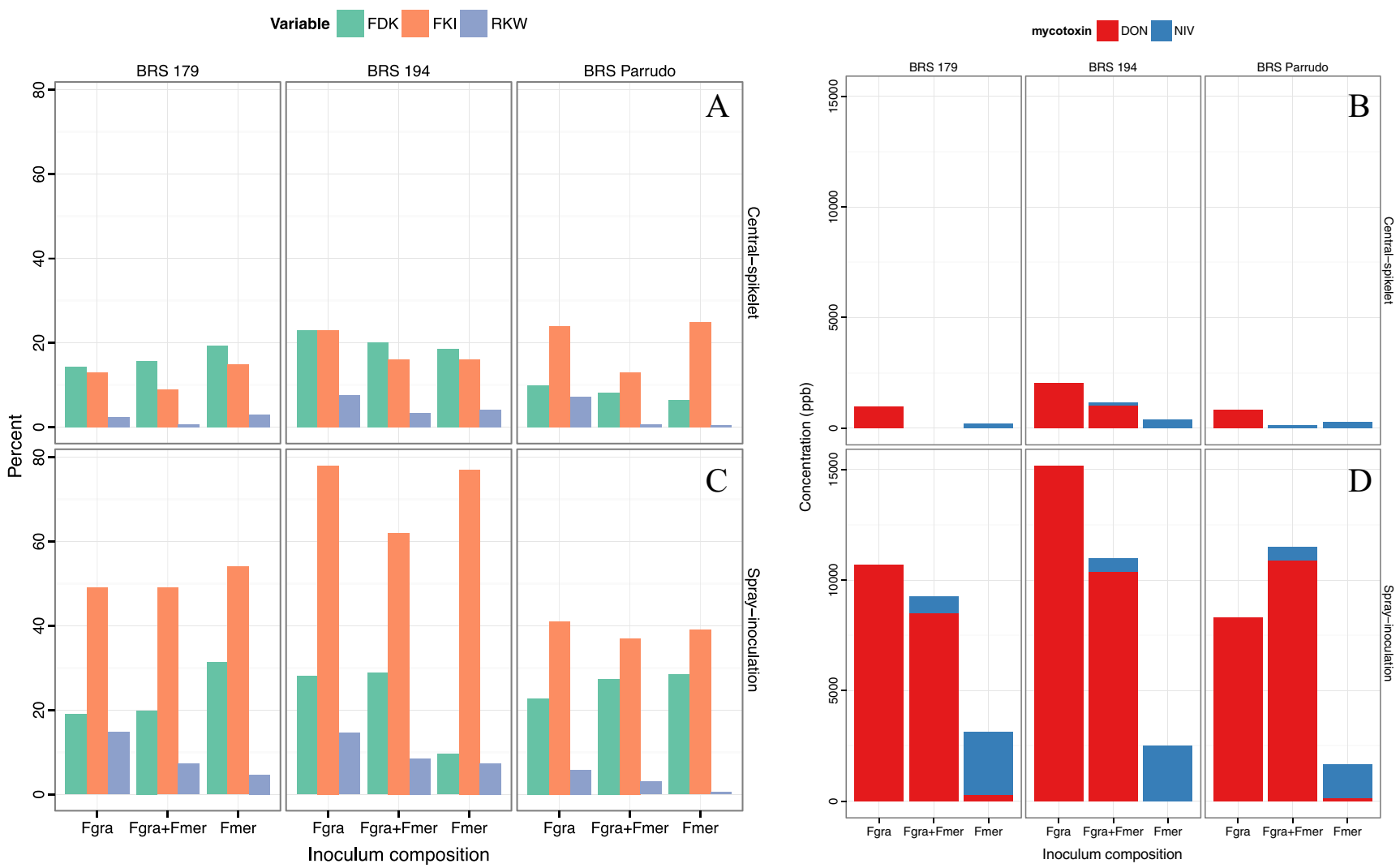

Fig. 2 Percent of Fusarium-damaged kernel (FDK), Fusarium kernel infection (FKI), reduction of kernel weight (RKW) (relative to noninoculated check treatment) (a and $\mathbf{c}$ ), and concentration of trichothecene mycotoxins (deoxynivalenol, DON and nivalenol, NIV) (b and d) evaluated on three EMBRAPA BRS cultivars inoculated at

central-spikelet inoculation method, have been reported with Fgra usually being the most aggressive species for infections

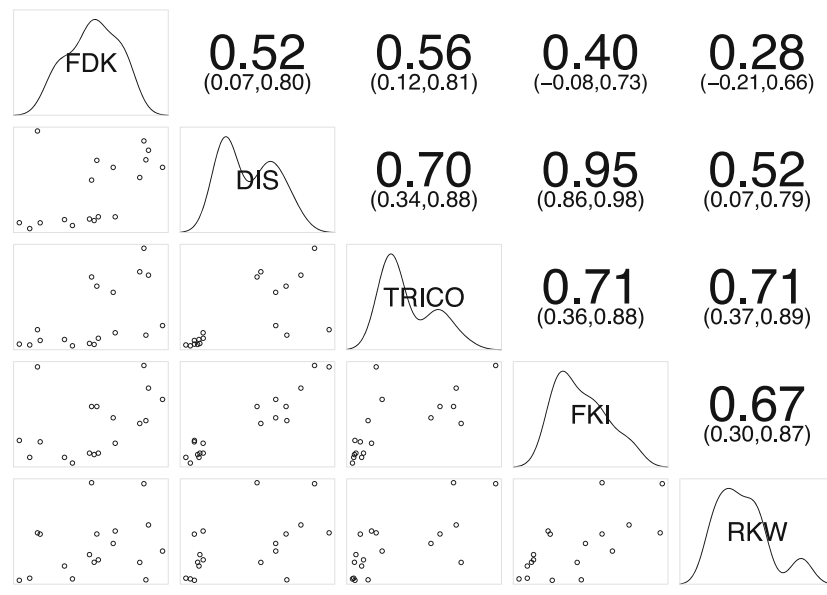

Fig. 3 Pearson's correlation coefficient and the respective $95 \%$ confidence interval calculated for all pairs among disease-variables (FKI Fusarium kernel infection, DIS Fusarium head blight incidence or severity), grain yield-related ( $R K W$ reduction in kernel weight) and amount of trichothecene $($ TRICO $=$ DON + NIV $)$. Correlation coefficient was calculated using 18 data points. Lower left panel scatterplot for the relationship. Diagonal panel density plot for the variable. Upper right panel correlation coefficient and confidence levels the early milk stage with three inoculum composition: Fusarium graminearum (Fgra) alone, F. meridionale (Fmer), alone, an the mixture of the two species (Fgra + Fmer (a). In a and $\mathbf{b}$, plants were inoculated using the central-spikelet inoculation method. In $\mathbf{c}$ and $\mathbf{d}$, spikes were spray-inoculated

during flowering (Toth et al. 2008; Goswami and Kistler 2005). In a greenhouse study using both spray and centralspike inoculation methods, Brazilian Fgra isolates were more aggressive than Fmer in a moderately resistant variety (BRS Guamirim) but similarly aggressive in a susceptible cultivar (BRS 194) suggesting a cultivar $\mathrm{x}$ species interaction (Spolti et al. 2012). However, in another study, 20 wheat genotypes were ranked similarly across eight species of the FGSC, suggesting that using a representative and aggressive species may allow breeders to achieve stable FHB resistance (Toth et al. 2008). In our experiment, the more advanced stage of the grain during the colonization by the fungus was likely limiting to disease spread from the inoculated spikelet for both species, thus preventing us to find differences regarding aggressiveness.

The patterns of kernel weight reduction suggest that Fgra was more damaging to grain yield compared to Fmer for spray inoculations performed after flowering. The higher damaging potential of Fgra compared to Fmer agrees with results from previous experiments with inoculations during flowering (Spolti and Del Ponte 2013). It is noteworthy that the new cultivar BRS Parrudo, which carries resistance to multiple stresses, including FHB, exhibited the lowest levels of kernel 
weight reduction in both inoculation assays, which may be due to multiple resistance mechanisms that are not restricted to visual symptoms (Mesterhazy 1995).

We found that the isolates used in this study were highly toxigenic, especially those of the Fgra species, which produced three to five times more total trichothecenes than Fmer. DON exceeded the maximum limit of tolerated for unprocessed wheat $(3,000 \mathrm{ppb})$ in all cultivars spray-inoculated with Fgra (ANVISA 2011). Fgra isolates produced only DON, and at much higher levels than Fmer, which produced mainly NIV but also trace levels of DON. Although it has been shown that the trichothecene genotype can be predictive of the chemotype, a few inconsistencies have been found (Mugrabi de Kuppler et al. 2011; Sampietro et al. 2012). In particular, in a collection of Fmer strains of the NIV genotype from maize grown in northwestern Argentina, three profiles were found: most isolates produced only NIV, but 41 out of 87 isolates produced mainly NIV and some amount of DON, which is in agreement with our findings (Sampietro et al. 2012). The eight FGSC members evaluated in the study by Toth et al. (2008) varied in aggressiveness and mycotoxin production, with Fgra and Fmer grouped as the most and least aggressive/toxigenic species, respectively, which agrees with another study that compared FGSC regarding pathogenicity and mycotoxin production (Goswami and Kistler 2005). The higher amount of DON from the mixed inoculum in our study may be due to a competitive advantage or higher toxigenic potential of Fgra compared with Fmer (Toth et al. 2008).

DON and NIV were detected in Brazilian commercial wheat grain, but mean DON was higher than mean NIV (Del Ponte et al. 2012). Our data suggests that NIV is indeed produced by Fmer and perhaps by the other three NIVproducing FGSC members commonly found with less frequency in Brazilian wheat: $F$ cortaderiae, $F$. asiaticum and $F$. austroamericanum, which deserves further investigation (Del Ponte et al. 2015). Collectively, our data and the previous report of NIV-producing species being less damaging to grain yield (Spolti and Del Ponte 2013), suggest that natural contamination of NIV may be due a combination of early and late infections that results in plump kernels infected by NIVproducing species, which are less damaging and so the kernels are less likely excluded during harvesting and postharvesting operations. This may contribute to the presence of levels of concern for a dangerous mycotoxin that is not currently regulated and commonly excluded from most routine analysis.

Acknowledgments The first author and second authors are grateful to the Programa de Pós-graduação em Fitotecnia (UFRGS) and CNPq Conselho Nacional de Desenvolvimento Científico e Tecnológico, for providing a $\mathrm{CNPq}$ graduate scholarship. The fourth and last author is thankful to $\mathrm{CNPq}$ for a research fellowship. Thanks are also extended to the staff at Embrapa Trigo for their technical support.

\section{References}

ANVISA (2011) Resolução RDC n 7, de 18 de fevereiro de 2011. Dispõe sobre limites máximos tolerados (LMT) para micotoxinas em alimentos. Diário Oficial da União, Poder Executivo, Brasília, 26 fev. 2011. Seção 1, page 66

Aoki T, Ward TJ, Kistler HC, O'Donnell K (2012) Systematics, phylogeny and trichothecene mycotoxin potential of Fusarium head blight cereal pathogens. JSM Mycotoxins 62:91-102

Astolfi P, dos Santos J, Schneider L, Gomes LB, Silva CN, Tessmann DJ, Del Ponte EM (2011) Molecular survey of trichothecene genotypes of Fusarium graminearum species complex from barley in southern Brazil. Int J Food Microbiol 148:197-201

Astolfi P, Reynoso MM, Ramirez ML, Chulze SN, Alves TCA, Tessmann DJ, Del Ponte EM (2012) Genetic population structure and trichothecene genotypes of Fusarium graminearum isolated from wheat in southern Brazil. Plant Pathol 61:289-295

Caierão E, Scheeren PL, Silva MS, Castro RL (2014) History of wheat cultivars released by Embrapa in forty years of research. Crop Breed Appl Biotechnol 14:216-223

Cheli F, Battaglia D, Gallo R, Dell'Orto V (2014) EU legislation on cereal safety: an update with a focus on mycotoxins. Food Control 37:315325

Del Ponte EM, Fernandes JMC, Pierobom CR, Bergstrom GC (2004) Giberela do trigo: aspectos epidemiológicos e modelos de previsão. Fitopatol Bras 29:587-605

Del Ponte EM, Fernandes JMC, Pierobom CR, Bergstrom GC (2007) Influence of growth stage on Fusarium head blight and deoxynivalenol production in wheat. J Phytopathol 155:577-581

Del Ponte EM, Buffon JG, Furlong EB (2012) Deoxynivalenol and nivalenol in commercial wheat grain related to Fusarium head blight epidemics in southern Brazil. Food Chem 132:1087-1091

Del Ponte EM, Spolti P, Ward TJ, Gomes LG, Nicolli CP, Kuhnem PR, Silva CN, Tessmann DJ (2015) Regional and field-specific factors affect the composition of Fusarium head blight pathogens in subtropical no-till wheat agroecosystem of Brazil. Phytopathology 105: 246-254

Desjardins A (2006) Trichothecenes. In: Desjardins A (ed) Fusarium mycotoxins: chemistry, genetics, and biology. The American Phytopathological Society, pp 13-64

Desjardins AE (2008) Natural product chemistry meets genetics: when is a genotype a chemotype. J Agric Food Chem 56:7587-7592

Geraldo MRF, Tessmann DJ, Kemmelmeier C (2006) Production of mycotoxins by Fusarium graminearum isolates from small cereals (wheat, triticale and barley) affected with scab disease in southern Brazil. Braz J Microbiol 37:58-63

Goswami RS, Kistler HC (2005) Pathogenicity and in planta mycotoxin accumulation among members of the Fusarium graminearum species complex on wheat and rice. Phytopathology 95:1397-1404

Lima MIPM, Só e Silva M, Schereen PL, Del Duca L de AJ, Pires JL, Nascimento Júnior A (2005) Avaliação de giberela em genótipos de trigo do ensaio estadual de cultivares, na região de Passo Fundo, em 2004. Embrapa Trigo. Documentos Online 52. Online: http://www. cnpt.embrapa.br/biblio/do/p_do52.htm

Lima MIPM, Só e Silva M, Caierão E, Schereen PL, Del Duca L de AJ, Nascimento Júnior A, Pires JL (2007) Avaliação de giberela em genótipos de trigo do ensaio estadual de cultivares, na região de Passo Fundo, em 2005. Embrapa Trigo. Documentos Online 66.Available online: http://www.cnpt.embrapa.br/biblio/do/p do66. $\mathrm{htm}$

McMullen M, Bergstrom G, De Wolf E, Dill-Macky R, Hershman D, Shaner G, Sanford DV (2012) A unified effort to fight an enemy of wheat and barley: fusarium head blight. Plant Dis 96:1712-1728

Mesterhazy A (1995) Types and components of resistance to Fusarium head blight of wheat. Plant Breed 114:377-386 
Miller JD, Greenhalgh R, Wang YZ, Lu M (1991) Trichothecene chemotype of three Fusarium species. Mycologia 83:121-130

Miller JD, Schaafsma AW, Bhatnagar D (2013) Mycotoxins that affect the North American agri-food sector: state of the art and directions for the future. World Mycotoxin J 1:1-20

Mugrabi de Kuppler AL, Steiner U, Sulyok M, Krska R, Oerke EC (2011) Genotyping and phenotyping of Fusarium graminearum isolates from Germany related to their mycotoxin biosynthesis. Int J Food Microbiol 151:78-86

O'Donnell K, Ward TJ, Geiser DM, Kistler HC, Aoki T (2004) Genealogical concordance between the mating type locus and seven other nuclear genes supports formal recognition of nine phylogenetically distinct species within the Fusarium graminearum clade. Fungal Genet Biol 41:600-623

Pagnussatt FA, Del Ponte EM, Buffon JG, Furlong EB (2014) Inhibition of Fusarium graminearum growth and mycotoxin production by phenolic extract from Spirulina sp. Pestic Biochem Physiol 108:21-26

Ramirez ML, Reynoso MM, Farnochi MC, Torres AM, Leslie JF, Chulze S (2007) Population genetic structure of Gibberella zeae isolated from wheat in Argentina. Food Addit Contam 24:1115-1120

Sampietro DA, Marín P, Iglesias J, Presello DA, Vattuone MA, Catalan CAN, Gonzalez Jaen MT (2012) A molecular based strategy for rapid diagnosis of toxigenic Fusarium species associated to cereal grains from Argentina. Fungal Biol 114:74-81

Schmale DG, Wood-Jones AK, Cowger C, Bergstrom GC, Arellano C (2011) Trichothecene genotypes of Gibberella zeae from winter wheat fields in the eastern USA. Plant Pathol 60:909-917

Spolti P, Del Ponte EM (2013) Agressividade diferencial de espécies do complexo Fusarium graminearum em interação com o fungicida tebuconazole na redução do rendimento de trigo. Ciência Rural 43:1569-1575

Spolti P, Barros NC, Gomes LB, dos Santos J, Del Ponte EM (2012) Phenotypic and pathogenic traits of two species of the Fusarium graminearum complex possessing either 15-ADON or NIV genotype. Eur J Plant Pathol 133:621-629

Spolti P, Shah DA, Fernandes JMC, Bergstron GC, Del Ponte EM (2015) Disease risk, spatial patterns and incidence-severity relationships of Fusarium head blight in no-till spring wheat following maize or soybean. Plant Dis. doi:10.1094/PDIS-09-14-0944-RE

Tanaka T, Yamamoto S, Hasegaw A, Aoki N, Besling JR, Sugiura Y, Ueno Y (1990) A survey of the natural occurrence of Fusarium mycotoxins, deoxynivalenol, nivalenol and zearalenone, in cereals harvested in the Netherlands. Mycopathologia 110:19-22

Thammawong M, Okabe M, Kawasaki T, Nakagawa H, Okadome H, Nakajima T, Kushiro M (2010) Distribution of deoxynivalenol and nivalenol in milling fractions from Fusarium-infected Japanese wheat cultivars. J Food Prot 73:1817-1823

Toth B, Kaszonyi G, Bartok T, Varga J, Mesterhazy A (2008) Common resistance of wheat to members of the Fusarium graminearum species complex and F. culmorum. Plant Breed 127:1-8

Umpiérrez-Failache M, Garmendia G, Pereyra S, RodríguezHaralambides A, Ward T, Vero S (2013) Regional differences in species composition and toxigenic potential among Fusarium head blight isolates from Uruguay indicate a risk of nivalenol contamination in new wheat production areas. Int J Food Microbiol 166:135140

Varga E, Glauner T, Köppen R, Mayer K, Sulyok M, Schuhmacher R, Krska R, Berthiller F (2012) Stable isotope dilution assay for the accurate determination of mycotoxins in maize by UHPLC-MS/MS. Anal Bioanal Chem 402:2675-2686

Ward TJ, Clear RM, Rooney AP, O’Donnell K, Gaba D, Patrick S, Starkey DE, Gilbert J, Geiser DM, Nowicki TW (2008) An adaptive evolutionary shift in Fusarium head blight pathogen populations is driving the rapid spread of more toxigenic Fusarium graminearum in North America. Fungal Genet Biol 45:473-484 